\title{
Mujer, publicidad y consumo en España. Una aproximación diacrónica*
}

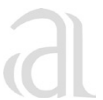 \\ Mercedes Montero \\ Recibido: 14 de diciembre de 2010 \\ Aprobado: 6 de febrero de 2011
}

\begin{abstract}
Resumen
La publicidad facilitó en España el paso de una sociedad de subsistencia a una moderna sociedad de consumo. El proceso discurrió durante el pasado siglo y tuvo dos momentos culminantes: el período de entreguerras y la década de los 60. En ambos casos, fue esencial el rol de la mujer. Primero, para insinuar el consumo en los años 20 y 30. Y segundo, para consolidarlo más tarde de manera ya definitiva. El presente artículo pretende analizar las circunstancias que hicieron de la mujer española la principal prescriptora de la publicidad y la gran aliada del consumo. Se quiso cimentar la modernidad sobre la mujer sin atender a las contradicciones que eso conllevaba: por una parte, la educación femenina se hallaba atrasada; por otra, se siguieron las teorías de la psicología experimental manteniendo -a la vez- los "clichés" tradicionales sobre la función de las mujeres en la sociedad.
\end{abstract}

Palabras-clave: publicidad, sociedad de consumo, España, mujer.

Este artículo de investigación científica y tecnológica pertenece a la investigación "Mujer, publicidad y consumo en España. Una aproximación diacrónica".

Universidad de Navarra (España). Correo electrónico: mmontero@unav.es 


\title{
Women, advertising, and consumption in Spain: a diachronic approach
}

\begin{abstract}
In Spain, advertising made transition of a survival society to a modern consumption society easier. The process took place during the last century and displayed two vital moments: a period between wars and the 60's. In both cases, the woman's role was vital, because women were used to promote consumption in the 20's and 30's and to consolidate consumption years later. This article is intended to analyze the circumstances around which Spanish women became the main advertising promoters and the most important allies of consumption. The intention was to base modernity on women without taking into account resulting contradictions: women's education was totally behind and experimental psychology theories were observed keeping traditional "clichés" about women's role in society.
\end{abstract}

Key words: advertising, consumption society, Spain, woman. 


\section{Introducción}

El pionero de la publicidad española fue Pedro Prat Gaballí, funcionario de la Cámara de Industria, Comercio y Navegación de Barcelona, que a principios del siglo XX introdujo en el país lo que entonces se llamaba "Publicidad científica". Es decir, aquella que siguiendo los métodos de la psicología experimental, el estudio racional del mercado, la organización de campañas y el esfuerzo creativo, lograba ser eficaz y provocar la decisión de compra por parte del consumidor. Prat fue un hombre de estudio, un auténtico erudito que llegó a conocer todo lo publicado hasta entonces en materia de publicidad. Y fue también un creador y un hombre de acción, ya que puso en marcha las primeras agencias modernas en el país, trabajando para las marcas más consolidadas del mercado español, como las de la perfumería Gal. Creó revistas profesionales, dictó cursos sobre publicidad, escribió libros sobre la materia y tradujo obras importantes como la de Hugo Munsterberg, Psicología de la actividad industrial.

Gracias a Prat y a sus seguidores, la publicidad vivió un momento de esplendor en el período de entreguerras, hasta 1936. Después de la Primera Guerra Mundial España empezó a desarrollarse económicamente y comenzó a apuntar una incipiente sociedad de consumo que, sin embargo, tuvo poca capacidad. Los mercados continuaron siendo locales, el comercio no terminó de desprenderse de sus vicios atávicos, y la publicidad por marca alcanzó a un segmento muy reducido de la industria nacional. Eso no obsta para que la potencialidad del mercado español fuera percibida por los profesionales atentos, españoles y extranjeros, que trabajaron a fondo para conseguir la penetración de sus productos. El uso de todos aquellos nuevos bienes de consumo suponía una mejora evidente en la calidad de vida de los españoles. Sin embargo, los medios publicitarios se hallaban en muy bajo nivel, aunque existían algunas agencias modernas, la mayoría eran de estilo decimonónico, y se limitaban a la compra-venta de espacios publicitarios. Los profesionales preparados eran escasos: abundaba el intrusismo de la peor especie. La prensa tenía poca difusión y era imposible conocer sus tiradas para establecer tarifas justas. Había pocas revistas ilustradas y en general de baja calidad. El cartel seguía en la cumbre, por tradición, pero se trataba de un medio que apenas era útil. Sin embargo, las modernas corrientes del arte vanguardistas, entre ellas la fotografía, pudieron entrar en España gracias a los carteles y anuncios. Según Prat, después de 30 años de lucha, solo el sector de perfumería, alguna marca de galletas (Artiach), el vino espumoso de Codorniú y el Anís el Mono eran marcas españolas bien asentadas. Lo demás -es decir, casi todo- estaba aún por hacer. Pero, curiosamente, lo que se había consolidado se debía fundamentalmente a la acción de la mujer.

\section{La principal aliada de la primera sociedad de consumo}

Entre los experimentos que llevaron a cabo los laboratorios de psicología estaban los realizados en los primeros años 20 por el doctor H.L. Hollingworth, de la Universidad de Columbia y los de Christine Frederick en 1928. Desde entonces se sabía que la mujer constituía el eje principal del consumo y hacia ella se dirigían la casi totalidad de las apelaciones publicitarias. Resultan tremendamente interesantes las apreciaciones que hacía Prat, en 1934, sobre el consumo, la publicidad y el papel de las mujeres en España. Lo son porque estaban basadas en una experiencia profesional de más de veinte años. Guiándose por lo que le había enseñando la práctica publicitaria, Prat afirmaba con convicción que si la mujer dejase de ver o leer anuncios, la publicidad perdería nueve décimas partes de su eficacia. Y continuaba:

[...] lo que equivale a afirmar que nueve décimas partes de las sumas invertidas en propaganda gráfica han de contar con el eterno femenino en el camino de su rendimiento. En dicha apreciación se reserva un porcentaje excesivamente modesto al libre albedrío del hombre; pero es evidente que gran parte de las ventas provocadas por el anuncio, aun tratándose de muchísimos artículos propios para caballeros, son debidas 
directa o indirectamente a la intervención de la mujer. Es muchas veces la hermana, la esposa o la novia quien elige nuestras corbatas, nuestros calcetines, nuestro bastón; es casi siempre la mujer la que se preocupa del confort y aprovisionamiento del hogar, siendo ella frecuentemente la que ejerce influencia sobre nuestras inversiones de dinero. El hombre, ocupado en los trabajos propios de su profesión, lee poco los anuncios; no tiene la curiosidad de la mujer ni le queda tiempo para tenerla. Ésta posee, en cambio, el instinto de enterarse de todo en forma tal, que esta curiosidad de algún modo influye sobre la sensibilidad de su carácter. Es lectora de anuncios y se constituye en preciosa intermediaria entre la publicidad y el hombre; por eso su acción es tanto más eficaz, a este respecto, cuanto más los anuncios contienen formas o expresiones que se adapten rápida e insensiblemente a las modalidades de su espíritu.

En el transcurso de nuestra práctica profesional hemos tenido ocasión de comprobar que algunas campañas fracasaban por no contar con la contribución de dicho elemento femenino" (Prat, 1934, 45-46).

Las apreciaciones psicológicas de Prat son propias de la psicología conductista de su época, que empezaban aplicarse a la actividad publicitaria. Ahora resultan anticuadas pero en los años 20 y 30 se alzaron como auténticos dogmas. Dejando estas consideraciones aparte, lo interesante de las afirmaciones de Prat es que están basadas en hechos de experiencia una y mil vecescomprobados: sin mujer, no habíapublicidad ni había consumo. Prat llegaba a hacer una recomendación muy atrevida para la época: que hubiera señoras trabajando en los departamentos creativos de las agencias que, si no redactasen los anuncios, dieran al menos ideas e hicieran sus observaciones sobre los resultados obtenidos. Hay que decir que en los Estados Unidos -el paraíso publicitario por antonomasia- el trabajo de la mujer en publicidad era ya una práctica habitual. En la central de JWT en Nueva York, el departamento creativo, donde se redactaban los anuncios, estaba dirigido por una mujer,
Helen Resor y compuesto exclusivamente por mujeres.

En el caso español, como indica Rodríguez Martín, no es exagerado afirmar "el papel protagonista que las mujeres tuvieron en la transformación social que durante el primer tercio del siglo XX llevó a la gestación de la sociedad de consumo" (Rodríguez Martín, 2007, 399).

Resulta sorprendente el hecho, pues la mujer apenas tuvo consideración en la sociedad española durante los años 20 y 30. España fue uno de los últimos países en conceder el voto femenino (1931). El número de mujeres con cierta educación era mínimo (un 6\% de chicas entre los universitarios españoles en 1930). El analfabetismo femenino, por el contrario, se hallaba en unos niveles exageradamente altos: en 1930 el 47,5\% de las mujeres españolas no sabían leer ni escribir. La cifra oscilaba de unas regiones a otras, entre el abrumador 66\% de Murcia y el más "llevadero" 26,7\% del País Vasco (Montero, 2009, 138). En tales circunstancias sorprende el hecho de que la creación de lo que se entendía como "modernidad" se estuviera cimentando sobre el grupo más débil y con menor influencia social.

\section{La mujer idealizada de la publicidad}

Quizá por ello la publicidad tendió a inventarse un tipo de mujer que se daba poco en la realidad. La mujer moderna e independiente que vemos en los anuncios de Perfumería Gal, y en las ilustraciones de los famosísimos dibujantes Federico Ribas y Rafael de Penagos, era más ilusión que realidad. Durante el período de entreguerras todo se llenó de mujeres elegantes que aparecían solas, en fiestas, paseando por la calle, conduciendo su automóvil, en bicicleta. Eran señoras que usaban cosméticos, jugaban al tenis, asistían a veladas de jazz, o usaban su máquina Kodak en los viajes de ocio y momentos de vacaciones (Arribas, 2005, 90). Una independencia o una emancipación que casaba mal con la realidad sociológica femenina de aquel momento.

Hubo algún anunciante que supo adaptarse mejor a la mujer real, aunque siempre con mati- 
ces. Uno de ellos fue Nestlé, industria alimentaria de origen suizo, asentada en España desde 1905. La propia naturaleza de sus productos hacía que éstos pudieran dirigirse a la mujer de extracción social alta, pero también a la de clase media e incluso obrera: la Harina Lacteada para ayudar al desarrollo de los niños en caso de intolerancia o de incapacidad de lactancia materna; o la leche condensada La Lechera que ofrecía la oportunidad de conseguir un alimento esencial, hasta entonces poco usado en la sociedad española por sus problemas de distribución, asociados a la rápida caducidad del producto en sí. Otro anunciante más cercano a la mujer real fue Maggi, también una empresa extranjera. Sus productos, caldos concentrados y sopas en pastillas, estaban pensados para un mercado más avanzado, donde la mujer ya trabajaba fuera del hogar. Ese tipo no era extraño en la Cataluña de los años 20 y 30, la región más industrializada de España, en cuyas fábricas había bastantes empleadas. Los productos Maggi iban dirigidos a un tipo femenino más acorde con la realidad; tuvieron, sin embargo, serios problemas para abrirse paso en España. Presentes desde 1916, no consiguieron asentarse hasta mediados de los años 20. Así explicaba Prat Gaballí el costoso éxito de los productos marca Maggi:

La idea de los mismos nació al compás de necesidades latentes sentidas por los elementos obreros y la clase media en las grandes capitales, donde el trabajo y la distancia dejan pocas horas libres, y donde los gastos de casa, trajes y diversiones limitan cada vez más la cantidad y la calidad de los alimentos, que, por otra parte, aumentan en sus precios, desproporcionados con los salarios. En esta invención, la publicidad, al amparar las primeras tentativas industriales, tuvo que vencer una importante resistencia: la repugnancia que nos inspira ingerir alimentos líquidos cuya composición no conocemos bien. Pero obsérvese que tal repugnancia era accidental -no substancial-, ya que, lejos de tratarse de la creación de una necesidad reñida con las costumbres, se trataba de la satisfacción real de conveniencias domésticas. Por esta razón fue relativamente fácil vencer las prevenciones momentáneas a fuerza de argumentos y determinar una necesidad entre ciertas clases sociales de algunos países (Prat, 1934, 138139).

Nadie podía imaginar a una sofisticada "chica Penagos" anunciando caldo concentrado Maggi, con cazuelas en la cocina, o criando a sus débiles hijos con Harina Lacteada Nestlé, y menos dedicada al mantenimiento de la casa. De cualquier forma, la publicidad de Nestlé -por ejemplosupo imprimir a estos quehaceres domésticos un cierto idealismo, tal y como quizá demandaba la estética del momento. Así, presentaba un modelo de esposa y madre concebido al estilo de moderno manager del hogar familiar. No en vano la publicidad conocía muy bien que la psicología humana necesitaba ser estimulada por ideas agradables y simpáticas para conseguir su fin. "No debemos presentar los objetos tal como son por sí mismo - decía James, uno de los psicólogos favoritos de Prat- sino [...] tal como existen en la imaginación humana" (Prat, 1934, 127). A la vista de los resultados podemos afirmar que la publicidad de los años 20 y 30 supo utilizar muy bien la imaginación humana para fabricar un atractivo ideal de mujer. Eso sí: ajeno a la realidad.

\section{Mujer y consumo en los años 50: antiguas tácticas y nuevos valores}

Tras la Guerra Civil (1936-1939) España se convirtió en un páramo donde el consumo fue prácticamente inexistente. En los años 50, sin embargo, la situación comenzó a cambiar y fue en esa década donde pudieron ponerse las bases de la moderna sociedad de consumo, que ya triunfaría definitivamente a partir de los años 60. De nuevo, las bases de esa sociedad volvieron a erigirse sobre la mujer.

Una encuesta realizada por el Instituto de Opinión Pública el año 1956, aportó un dato de decisiva importancia: las mujeres oían más la radio que los hombres. García Ruescas, publicitario de la época y autor de numerosos libros sobre la materia, explicaba: 
Como la mujer representa un factor muy importante en la publicidad -ya que es precisamente ella quien determina el mayor número de compras que se realiza en sus hogares-, a ella se ha de dirigir la mayor parte de la propaganda que se hace por radio. Se la ha de hablar de las ventajas, de la economía que supone la compra del producto anunciado. Se ha de argumentar diciendo que el marido, el hermano, el hijo se sentirán mejor, más satisfechos con el empleo de la marca deseada (García Ruescas, 1957, 354-355).

Como vemos, el papel de la mujer como principal consumidora seguía siendo de vital importancia. Casas Santasusana, otro autor de la época, ponderaba en 1954 el valor de la mujer como compradora de productos. De su decisión dependían los alimentos, los artículos para niños, la mayor parte de las prendas de vestir y prácticamente todos los objetos del hogar. A la "compradora por excelencia" se le dedicaban muchos espacios de radio, pero según Casas, no se estaba intentando la captación del público femenino de manera especial. Había que empeñarse más porque el binomio radio-mujer encerraba mucha potencialidad, puesto que el ama de casa hacía compatible escuchar la radio con realizar las tareas del hogar. Por lo tanto, se podían enviar mensajes publicitarios que captaran su atención no sólo en los programas dedicados a ella, sino en todos los demás. Alertaba también este autor sobre el cambio de costumbres que se estaba empezando a registrar en el universo femenino. En este sentido, la tendencia moderna era que la mujer pasara más tiempo fuera de casa, y por otra parte había que llamar la atención de las nuevas generaciones. A las chicas jóvenes les gustaba la calle, eran amantes de las diversiones y el deporte y estudiaban o trabajaban en un porcentaje más alto de lo que lo hicieron sus madres. Ciertamente las muchachas tenían muy poca capacidad adquisitiva, pero programas de música o de moda, patrocinados por alguna perfumería o negocio similar podrían resultar muy atractivos (Casas, 1954, 101-105).

Ciertamente la mujer estaba cambiando. Anunciantes tradicionales como Nestlé ya se habían percatado. El mercado español era una copia retrasada de otros donde Nestlé había arraigado y por lo tanto podía intuir la evolución de éste. En los años 50 se adelantó a las necesidades de las consumidoras presentando nuevos productos que tenían ya una incipiente demanda. Estaba apuntando una nueva clase media y Nestlé salió en su ayuda con el puré de patatas, los cubitos de caldo, las sopas y cremas, todo ello de la marca Maggi (por entonces ya absorbida por Nestlé) (Velarde, 2005, 15). Pero los años 50 fueron esencialmente los de Nescafé. Llegado al mercado español en 1955 resultó el producto estrella de la casa junto a La Lechera. De hecho la salida al mercado de Nescafé se apoyó publicitariamente en la leche condensada de esa marca.

La publicidad de Maggi y Nescafé buscaba ya a otra mujer distinta. En el período de entreguerras Nestlé se había dirigido al ama de casa considerándola "manager" del hogar. En los años 50, sin descuidar esta imagen, el enorme éxito de Nescafé puso en primer plano a una mujer dinámica, en cierto sentido, ya equiparada al hombre, que prepara rápidamente un café con leche al compás de la vida moderna, en casa o en el trabajo. Un nuevo imaginario social empezaba a configurarse a través de los productos Nestlé:

En la década de los 50 del siglo XX Nestlé introdujo algunas nuevas revoluciones alimentarias que anunciaban la explosión de la demanda de alimentos-servicio o de conveniencia que se produciría a partir de la década siguiente. Facilidad, comodidad o rapidez son términos que cada vez más expresan nuevas demandas, sobre todo a partir del momento en que la escasez y el racionamiento empiezan a superarse. El café instantáneo Nescafé es un buen ejemplo de todo ello, puesto que permite prescindir de la 'incomodidad del filtro y de la cafetera'. Se prepara 'tan fácilmente' que puede tomarse en 'cualquier lugar' y en 'cualquier momento'. El café se liga cada vez más no tanto con su poder estimulante sino curiosamente con un efecto relajante, al asociarlo con la pausa, el descanso, la conversación amigable y la ruptura de la monotonía y de las rutinas laborales. Precisamente otra de las caracte- 
rísticas que se atribuirán a la modernidad, el ritmo trepidante de vida, puede alternarse fácilmente con la relación de un café fácil de preparar sin trastornar el horario. Incluso en verano puede prepararse 'al instante un delicioso café helado' (Contreras, 2005, 59-60).

\section{La mujer y el trabajo en la publicidad}

La publicidad estaba apegada a la figura femenina desde sus orígenes. Jaime Vicens escribía en 1954: "con medios tan expresivos como son el dibujo estilizado, el humorístico y, sobre todo, la fotografía, se comprende que la mujer, por sí misma, haya bastado para ser la cúspide del anuncio" (Vicens, 1954, 183). Pero, a pesar de las acciones de Nestlé, en el ámbito de la publicidad española no cabía todavía pensar en la mujer "para la exhibición gráfica de alardes o sugestiones profesionales" (Vicens, 1954, 191). Desde el punto de vista del lector de anuncios -afirmaba este autor- la mujer no había adquirido el suficiente prestigio profesional, "ni mucho menos". Situar una figura femenina en el despacho legal o en la consulta del médico se consideraría un burdo anzuelo. Utilizar al hombre abogado o médico, en cambio, daría a cualquier anuncio toda su fuerza convincente y sugestiva:

La ciencia ha sido alcanzada por los hombres en general. Por esto, siempre que la mujer fuera empleada como motivo de 'cientifismo' fracasaría el anuncio, porque daría de bruces con la idea de una forzada popularidad, es decir, quitaría seriedad al asunto al descubrir la intención de querer seducir al lector con el espejuelo de la mujer empleada como ardid publicitario.

No quiere ello decir que en Puericultura no pueda tener su atractivo la 'nurse' especializada, pero siempre la palabra y la figura del médico merecerán en el pueblo español [...] una mayor confianza, produciendo por ende mayor rendimiento el anuncio orientado en este sentido" (Vicens, 1954, 193).

La mujer, profesional y publicitariamente hablando, solo llegaba a ciertos menesteres, como mecanógrafa o secretaria. En esas ocupaciones laborales sí detentaba "el privilegio social de la solvencia, mientras en ciertas otras (abogacía, por ejemplo) es todavía motivo decorativo" (Vicens, J., 1954, 191). Se respetaban los roles establecidos: "si queremos anunciar materia culinaria, indudablemente puede aparecer un cocinero, pero la generalización del artículo aboga por el empleo de la tradicional figura del ama de casa" (Vicens, 1954, 184).

Puesto que el publicitario lo que quiere es vender, es decir, se mueve en el ámbito de la más cruda realidad material, podemos dar carta de autoridad a las palabras de Vicens. La mujer contaba poco en la vida laboral y, por consiguiente, en cierto tipo de publicidad. "Afortunadamente" las industrias de jabones detergentes, perfumería o confección, estaban más extendidas, gozaban de más popularidad y producían más beneficios que las dedicadas a la fabricación de fonendos o bisturíes. Y favorecían más la configuración de la sociedad de consumo, que de eso se trataba.

\section{Psicología barata}

A estos hechos habría que añadir las teorías psicológicas clásicas introducidas por Prat. Según éstas, para conseguir la efectiva acción de compra era necesario fomentar el espíritu de competencia y la emulación. Y ambas características estaban mucho más desarrolladas en el sexo femenino, lo que llevaba a la mujer a interesarse por la mujer misma. De ahí un motivo básico más para emplear su figura en la publicidad. Pero -afirmaba Vicensesta estrategia debía utilizarse con honradez, porque:

Especialmente en las capas sociales más humildes, muchos anuncios protagonizados por una muchacha que cuenta maravillas inducen al gasto superfluo, crean una torcida mentalidad sobre ciertos conceptos y no hacen más que engañar burdamente bajo la capa de desconfianza que reside en las embaucadoras confesiones de mujer a mujer [habla de titulares tipo 'cómo me casé con un millonario', 'diez años más joven', 'unos ingredientes mágicos que devuelven la juventud']. 
La mujer actuando como testigo, ya ilusorio, ya real ha causado graves prejuicios en las mentes ingenuas o alucinadas de miles de lectoras (Vicens, 1954, 187).

Se trata de ejemplos de publicidad parasitaria, de publicidad mal hecha, de publicidad mentirosa, la cual había sido siempre muy abundante en el mercado español. El público femenino era más proclive a caer en semejantes necedades porque sus niveles de formación en la España del momento eran todavía ridículos. Por este motivo pensamos que sobraba psicología experimental en los análisis de los técnicos publicitarios y faltaba enseñanza secundaria y universitaria entre las mujeres. En 1950 sólo el 14,55\% de los estudiantes universitarios españoles eran mujeres y faltaban casi 30 años para que las cifras se igualaran a las de los varones (Barrera Peña, López Peña, 1983, 191-192).

Otro tema que es necesario abordar es el de la utilización publicitaria del cuerpo femenino. Es un lugar común en la bibliografía destacar el papanatismo de los anuncios de corsetería, ropa interior, modas y artículos de higiene femenina en general. Hay que decir que tal modo de hacer no era exclusivo de la España franquista, sino práctica bastante habitual de la publicidad en aquellos momentos. En su libro Cómo debe anunciarse en los periódicos, Vicens toca ampliamente este tema poniendo como ejemplo anuncios de Estados Unidos y de Alemania. A las mujeres de los años 50 les interesaba la publicidad de artículos de ropa interior o de higiene íntima, pero también querían discreción: "las mismas señoras no gustan de que esa publicidad especial que a ella atañe sea colocada sin ton ni son en una sección improcedente o entre las páginas para niños, por ejemplo" (Vicens, 1954, 146). Ese tipo de artículos eran tan frágiles en manos de la publicidad como los que combatieron el mal aliento o el mal olor corporal en los años 20. Se entendía que había cuestiones que debían ser tratadas con discreción para obtener resultados publicitarios óptimos (como los de Listerine u otras marcas de higiene personal en su momento). Por tanto, según Vicens, ¿qué perseguían ciertos anuncios de ropa interior donde el realce y la pose exage- rada caían en la sensualidad? Porque, "aquellos mozalbetes que contemplan embobados la foto publicitaria con seguridad no consumirán el artículo". La argumentación no carece de sentido común.

Se olvida con demasiada frecuencia que la revolución sexual generalizada es un fenómeno de los años 60, no de las décadas anteriores. Por eso podía afirmar Vicens en 1954 que "el publicitario no ha de ser un mojigato, pero sí un hombre responsable y, dentro de un amplio campo para desenvolverse libremente, un moralista de la publicidad" (Vicens, 1954, 189). Es decir, el encargado de discernir sobre el bien y el mal.

\section{Conclusiones}

1. Durante los años 20 y 30 España experimentó cambios sociales importantes, cuyo motor fue la publicidad. Un buen ejemplo lo tenemos en el sector de la perfumería e higiene femenina, donde los anuncios construyeron un prototipo de mujer moderna y emancipada, situándola habitualmente en ambientes sofisticados o deportivos. Otros bienes de consumo pusieron su grano de arena para consolidar esta imagen de independencia: las cámaras fotográficas Kodak, la publicidad de automóviles o las ilustraciones de Penagos para todo tipo de marcas. Nada era más ajeno a la mujer española de los años 20 y 30 que la emancipación. Si la publicidad hubiera reflejado la realidad social del momento, tendría que haber construido sus reclamos sobre $47,5 \%$ de la población femenina analfabeta (en 1930). O sobre la práctica totalidad de las mujeres, sujetas jurídicamente a su padre hasta el matrimonio y a sus maridos después. Si Gal, Myrurgia o Floralia se hubieran ceñido a este tipo de realidades, es posible que no hubieran prosperado. Por eso recrearon un ideal, al que quizá muchas mujeres aspiraban.

2. De nuevo en los años 50 se empezaron a poner las bases de una nueva sociedad de consumo en España. Esta vez el intento tuvo éxito y se llegó así al desarrollismo econó- 
mico de los años 60 y 70. La publicidad jugó un papel esencial en este cambio y volvió a apoyarse en el universo femenino, adoptando nuevas manera de hacer, pero yendo siempre un paso por delante de la verdadera mujer de carne y hueso.

3. Tal modo de comportarse en los dos momentos clave del desarrollo publicitario español hacen pensar que esta actividad no se limita a ser un mero reflejo de la sociedad, como algunos autores pretenden. Por el contrario, está llamada a cambiar las costumbres, por su misma naturaleza, ya que introducir nuevos productos significa habitualmente crear nuevas necesidades. La publicidad no tendría razón de ser ni no persiguiera tales objetivos. Por eso, cuando la realidad es tan densa que no se puede modificar, se intenta al menos reinventarla, sugerir que podría ser de otra manera si los productos que se anuncian llegaran a utilizarse.

\section{Referencias bibliográficas}

Arribas, J. M. (2005) "Nestlé: paradigma de la comunicación publicitaria", Nestlé en España, 105-2005. Reflexiones sobre su contribución al desarrollo económico y social, Nestlé España, S.A. Esplugues de Llobregat.

Barrera Peña, M. L. y López Peña, A. (1983) Sociología de la mujer en la Universidad: Análisis histórico-comparativo, Santiago de Compostela, Universidad de Santiago de Compostela.

Casas Santasusana, E. (1954) Cómo se vende por anuncio, J. Bruguer, Barcelona.
Contreras, J. (2005) "Cien años de Nestlé, cien años de alimentación en España", Nestlé en España, 105-2005. Reflexiones sobre su contribución al desarrollo económico y social, Nestlé España, S.A. Esplugues de Llobregat.

García Ruescas, F. (1957) Manual de Publicidad, Gráficas IMCO, Madrid, $2^{\text {a }}$ edición.

Montero, M. (2009) La conquista del espacio público. Mujeres españolas en la Universidad, 1910-1936, Minerva, Madrid.

Montero, M., Rodríguez Salcedo, N., Verdera, F. (2010) De la nada al consumo. Historia de la Publicidad y de las Relaciones Públicas en España, Comunicación Social ediciones y publicaciones, Sevilla.

Munsterberg, H. (1914) Psicología de la actividad industrial. Ensayo de psicología experimental aplicada, Daniel Jorro editor, Madrid.

Prat, P. (1934) Publicidad racional, Editorial Labor, S.A., Barcelona.

Rodríguez Martín, N. (2007) La imagen de la mujer en la publicidad gráfica en España en el primer tercio del siglo XX, Archiviana, Madrid.

Vicens, J. (1954) Como debe anunciarse en los periódicos, Juan Bruguer editor, Barcelona.

Velarde, J. (2005) "Introducción", Nestlé en España, 105-2005. Reflexiones sobre su contribución al desarrollo económico y social, Nestlé España, S.A. Esplugues de Llobregat. 